\title{
Ação antrópica na incidência dos focos de calor na Microrregião de Paragominas, Estado do Pará, Norte do Brasil
}

\section{Lucas Oliveira Araújo ${ }^{1}$, Ernandes Macedo da Cunha Neto², Marcio Roberto da Silva Melo ${ }^{3}$, Núbia de Fátima Alves dos Santos $^{3}$ e Luciana da Silva Borges ${ }^{3}$}

\author{
${ }^{1}$ Universidade Federal Rural da Amazônia. Campus Paragominas. Curso de \\ Graduação em Engenharia Florestal. Rodovia PA-256, km 06. Bairro Nova \\ Conquista. Paragominas-PA, Brasil (CEP 68627-451). \\ ${ }^{2}$ Universidade Federal do Paraná. Programa de Pós-Graduação em Engenharia \\ Florestal. Av. Prefeito Lothário Meissner. Jardim Botânico. Curitiba-PR, Brasil \\ (CEP 80210-170). E-mail netomacedo878@gmail.com. \\ ${ }^{3}$ Universidade Federal Rural da Amazônia. Campus Paragominas. Rodovia PA-256, \\ km 06. Bairro Nova Conquista. Paragominas-PA, Brasil (CEP 68627-451).
}

Resumo. O fogo é um instrumento do desflorestamento, devido seu emprego na conversão de vegetação em pastagens e agricultura, sendo difícil monitorá-lo, devido à grande dimensão do Estado do Pará. 0 sensoriamento remoto e o geoprocessamento são alternativas que favorecem esse monitoramento. Assim, objetivou-se avaliar a dinâmica dos focos de calor na Microrregião de Paragominas, Estado do Pará, Norte do Brasil, sob a ótica do desmatamento e agricultura. Utilizou-se vetores dos focos de calor, desmatamento e agricultura, sendo analisados em escala multitemporal, entre os anos de 2002 e 2018. No período de 2002 a 2006 houve um incremento de $128,75 \%$ dos focos de calor e redução de $75,71 \%$ do desmatamento. Entre 2006 e 2010 os focos de calor e áreas desmatadas reduziram. De 2010 a 2014 os focos de calor cresceram, enquanto o desmatamento reduziu. De 2014 a 2018 os focos reduziram em aproximadamente 92\%. Houve grande crescimento da agricultura entre 2002-2018. 0 alto desmatamento e focos de calor entre 2000 e 2008, deve-se a exploração madeireira, principal renda da microrregião na época. As políticas de combate ao desmatamento, aliadas à moratória da soja foram essenciais para contê-lo. Os focos concentraram-se nos assentamentos, agricultura, desmatamento e rodovias. Não houve concentração em terras indígenas. Os fatores antrópicos influenciam na dinâmica espaço-temporal dos focos de calor, uma vez que convertem a floresta densa em áreas de vegetação pouco densa, aumentando a absorção de calor pelo solo. Deve-se intensificar políticas públicas para conscientizar os agricultores
Recebido $01 / 05 / 2020$

Aceito

$17 / 10 / 2020$

Disponível on line $18 / 10 / 2020$

Publicado $31 / 12 / 2020$

Acesso aberto

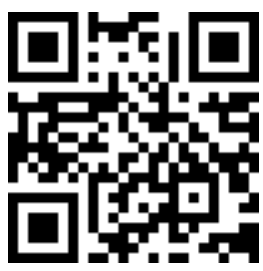

ORCID

(D) 0000-0002-1584-5351 Lucas Oliveira Araújo

ISSN 2359-1412/RBGAS-2020-0069/2020/7/17/8/1153

Rev. Bras. Gest. Amb. Sustent.

http://revista.ecogestaobrasil.net 
familiares sobre o uso do fogo, bem como fomentar técnicas alternativas e garantir assistência técnica.

Palavras-chave: Agricultura; Desmatamento; Fogo; Kernel.

Abstract. Anthropic action on hotspot incidence in Paragominas Microregion, Pará State, North Brazil. Fire is an instrument of deforestation, its use in the conversion of vegetation into pasture and agriculture, and it is difficult to monitor it, due to the large size of the state of Pará. Remote sensing and geoprocessing are alternatives that favor this monitoring. The objective of this study was to evaluate the dynamics of heat sources in the Paragominas Microregion, Pará State, North Brazil, from the perspective of deforestation and agriculture. Vectors of the foci of heat, deforestation and agriculture were used and analyzed on a multitemporal scale, between the years 2002 and 2018. From 2002 to 2006, there was an increase of $128.75 \%$ in the heat zones and a reduction of $75.71 \%$ in deforestation. Between 2006 and 2010 hotspots and deforested areas reduced. From 2010 to 2014 hotspots grew, while deforestation decreased. From 2014 to 2018 hotspots reduced by approximately $92 \%$. There was great growth in agriculture between 2002-2018. The high deforestation and heat zones between 2000 and 2008 were due to logging, the main income of the micro-region at the time. Policies to combat deforestation, combined with the soy moratorium were essential to contain it. The focus was on settlements, agriculture, deforestation and roads. There was no concentration on indigenous lands. Anthropic factors influence the space-time dynamics of hotspots, since they convert dense forest into areas of low vegetation, increasing heat absorption by the soil. Public policies should be intensified to make family farmers aware of the use of fire, as well as to foster alternative techniques and ensure technical assistance.

Keywords: Agriculture; Deforestation; Fire; Kernel.
(D) 0000-0001-6775-0365

Ernandes Macedo da

Cunha Neto

(D) 0000-0002-2649-8869

Marcio Roberto da

Silva Melo

0000-0001-7725-1412

Núbia de Fátima Alves

dos Santos

(D) $0000-0002-1194-6411$

Luciana da Silva

Borges

\section{Introdução}

A floresta amazônica é imprescindível para a conservação da biodiversidade, bem como manutenção do ciclo hidrológico, sendo a maior floresta tropical do planeta (Aragão, 2012). Apesar disso, o intenso processo de ocupação desse bioma, aliado ao desmatamento proveniente da abertura de terras para agricultura e pecuária, vem ocasionando serias injúrias para sua fauna e flora.

Neste contexto, o estado do Pará está entre os três estados da Amazônia com a maior área desmatada desde 2004, de tal maneira que no ano de 2018 foi responsável por $36,4 \%$ do desmatamento desse bioma (INPE, 2019). Desta área, aproximadamente $30 \%$ foi desflorestada na mesorregião sudeste do estado, sendo a microrregião de Paragominas responsável por quase $12 \%$ do desmatamento desta.

Entre os principais instrumentos do desflorestamento, destaca-se o fogo, devido sua utilização na conversão de vegetação em áreas de pastagens e agricultura (Aragão e 
Shimabukuro, 2010; Armenteras e Retana, 2012; Devisscher et al., 2016a). Dessa forma, entende-se que a ocorrência das queimadas siga os padrões do desmatamento e expansão agrícola, contudo, poucos estudos relacionaram esses fatores, principalmente em uma escala espaço-temporal (Lima et al., 2012; Middendorp et al., 2013). Entretanto, a grande dimensão territorial do estado do Pará, prejudicam o monitoramento e a fiscalização pelos órgãos competentes, dificultando a coleta de informação para elaboração desses estudos.

Uma alternativa ao monitoramento ambiental é o sensoriamento remoto e o geoprocessamento, uma vez que essas ferramentas favorecem o acompanhamento periódico de grandes áreas, com informações precisas do posicionamento geográfico e dimensão do desmatamento, queimadas e uso da terra (INPE, 2020a). Na questão das queimadas, a detecção dos focos de calor, por satélites, é um instrumento que auxilia a identificação das áreas afetadas ou propicias a ação do fogo (Bittencourt et al., 2013).

Um dos métodos favoráveis para acompanhar a dinâmica desses focos é o estimador de densidade de kernel, uma vez que gera mapas que indicam as concentrações desses focos (Koutsias et al., 2004), possibilitando a automatização no monitoramento das queimadas e compreensão das suas causas.

Assim, com vistas em fomentar a compreensão da influência antrópica na dinâmica espaço-temporal das queimadas, objetivou-se avaliar a dinâmica dos focos de calor na microrregião de Paragominas-PA sob ótica da expansão do desmatamento e fronteira agrícola.

\section{Material e métodos}

\section{Área de estudo}

0 estudo foi realizado na Microrregião de Paragominas, pertencente a Mesorregião Sudeste Paraense, sendo composta por sete municípios, Abel Figueiredo, Bom Jesus do Tocantins, Dom Elizeu, Goianésia do Pará, Paragominas, Rondon do Pará e Ulianópolis (Figura 1). 0 ponto central da área de estudo está entre as coordenadas geográficas $3^{\circ} 50^{\prime} 22,598^{\prime \prime}$ S e $47^{\circ} 54^{\prime} 43,57^{\prime \prime}$ W.

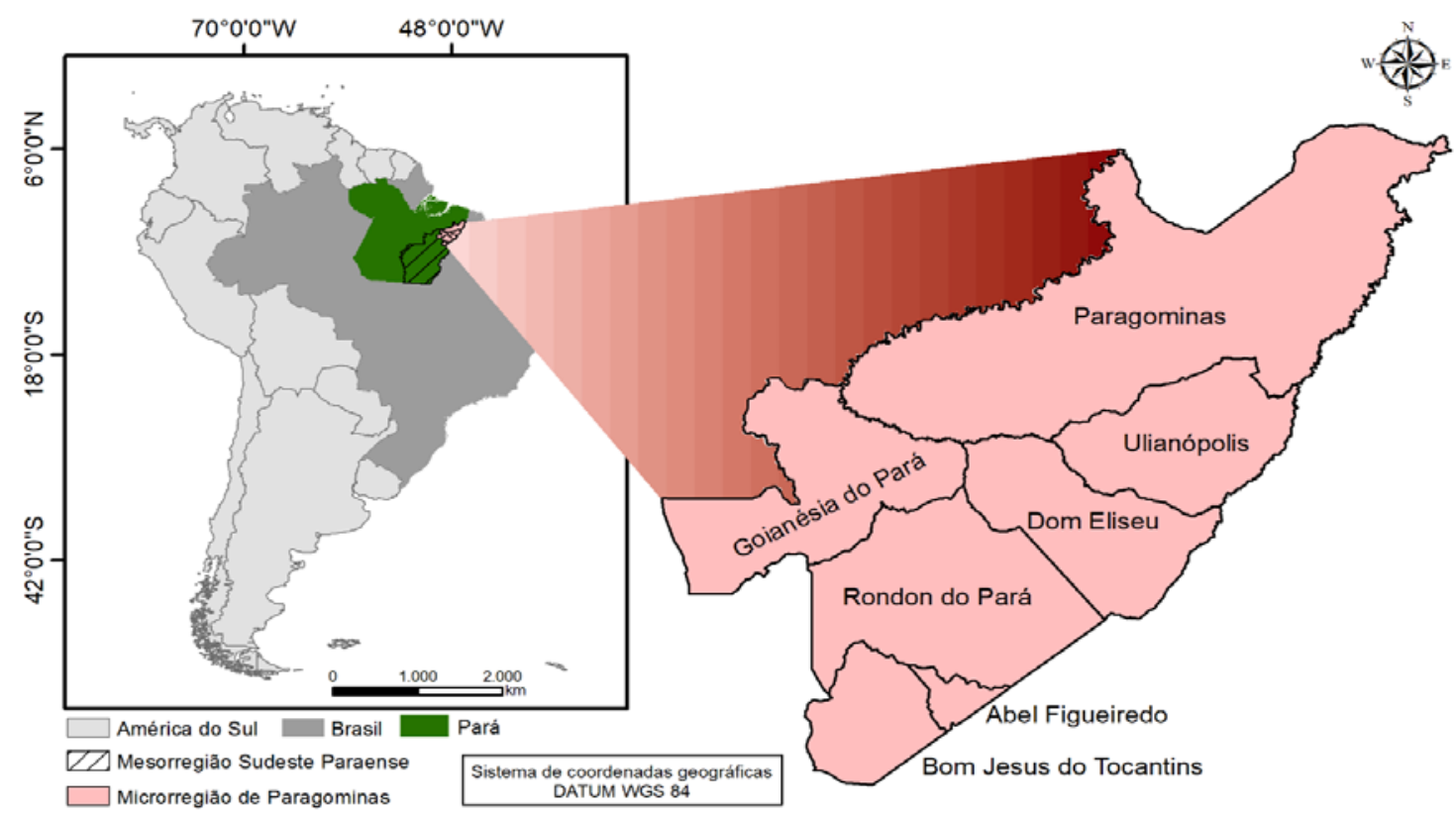

Figura 1. Microrregião de Paragominas, Pará. 
A microrregião possui o clima do tipo $\mathrm{A}$, segundo a classificação climática de Köppen, com temperatura média $26,3{ }^{\circ} \mathrm{C}$ e umidade relativa do ar $81 \%$, com precipitação média anual de $1.800 \mathrm{~mm}$ (Alvares et al., 2013). Neste local há dois períodos climáticos: Chuvoso e seco, sendo o chuvoso dos meses de outubro até de maio, e seco compreende os meses de junho a setembro (Albuquerque et al., 2010). Os solos predominantes na área são classificados como Latossolo Amarelo, textura média a alta, e de baixa fertilidade natural (Santos et al., 2018).

\section{Aquisição dos dados}

$\mathrm{Na}$ base de dados do Instituto Nacional de Pesquisas espaciais (INPE) foram adquiridos os vetores referentes aos focos de calor e o desmatamento, nos programas Queimadas (INPE, 2020b) e PRODES (INPE, 2019). Os dados referentes à agricultura foram obtidos no portal MAPBIOMAS (Mapbiomas Development Team, 2019). Além disso, no Instituto Brasileiro de Geografia e Estatística - IBGE, obteve-se os arquivos vetoriais da divisão política do Estado do Pará, das terras indígenas, bem como das áreas de assentamentos rurais, foi utilizado ainda, vetor correspondente e malha rodoviária (IBGE, 2019). Todos os dados mencionados foram adquiridos de maneira gratuita em sítios eletrônicos das referidas instituições governamentais.

\section{Processamento dos dados}

Esses dados foram analisados em escala multitemporal, entre os anos de 2002 e 2018, em um intervalo de quatro anos, compreendendo os anos de 2002, 2006, 2010, 2014 e 2018. Os focos de calor foram utilizados para geração dos mapas de densidade de kernel, a fim de averiguar onde estes se concentram e o seu raio de influência. Posteriormente, os vetores do desmatamento, agricultura, assentamentos, terras indígenas e rodovias foram inseridos juntos aos mapas de densidade, com vistas em observar a influência desses na ocorrência dos focos de calor. Vale ressaltar que todo o processamento foi realizado no software QGIS versão 2.18 (QGIS Development Team, 2016).

\section{Resultados}

O ano 2002 foi o que apresentou maior área desmatada do período e menor agricultura, de modo que houve uma constante redução do desmatamento e alta evolução da fronteira agrícola até 2018. Em contrapartida, a maior incidência dos focos foi registrada em 2006 e 2014. (Figura 2).

No período de 2002 a 2006 houve um incremento de $128,75 \%$ dos focos de calor, aliado a uma redução de $75,71 \%$ do desmatamento e alta taxa de expansão da fronteira agrícola. Já entre 2006 e 2010 os focos de calor e áreas desmatadas reduziram, enquanto as áreas agrícolas aumentaram. 0 período 2010-2014 evidenciou o crescimento dos focos de calor, redução do desmatamento e crescimento de $218,93 \%$ das áreas agricultáveis. De 2014 a 2018 os focos reduziram em aproximadamente 92\%, enquanto o desmatamento e a agricultura cresceram (Tabela 1 ). 


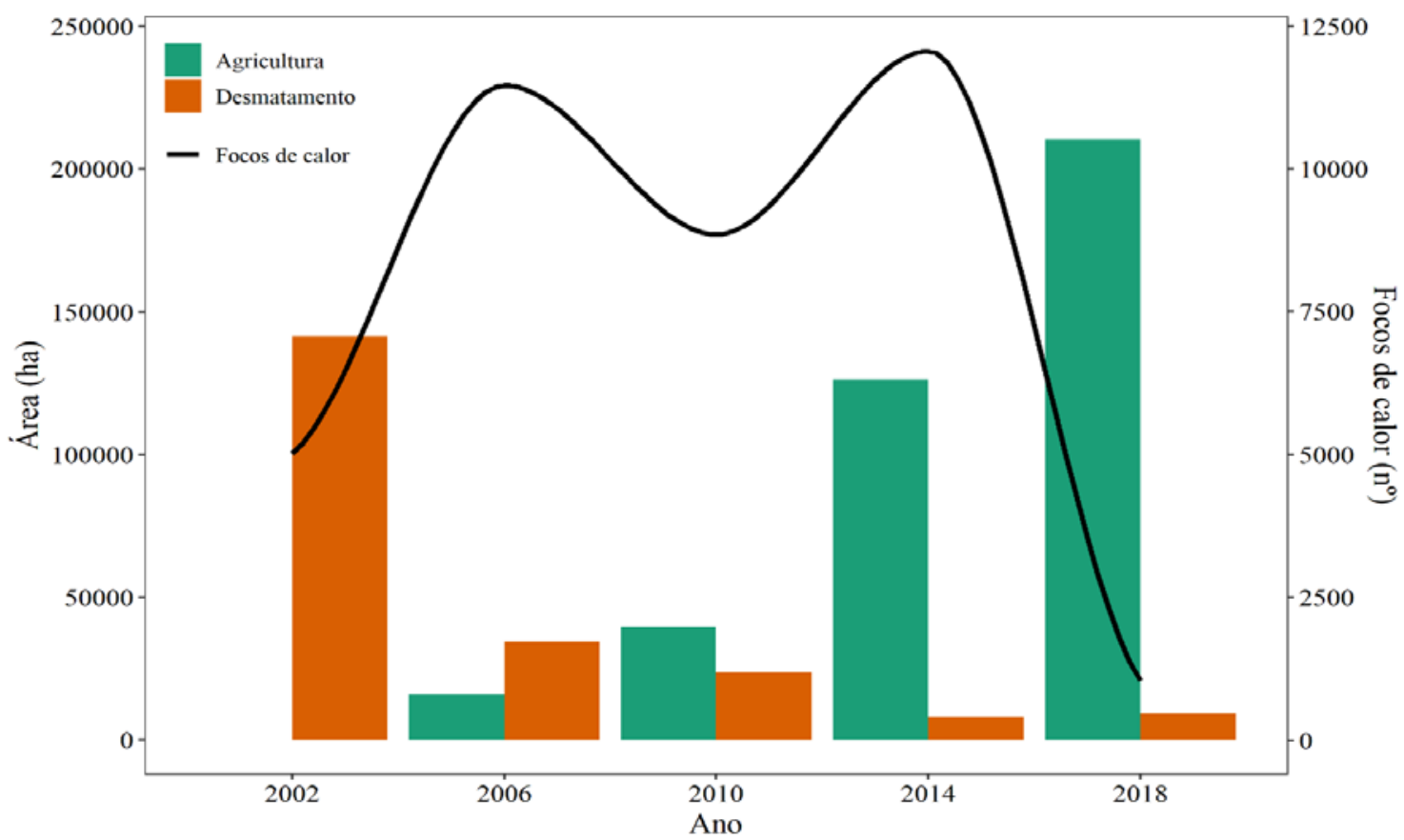

Figura 2. Focos de calor, desmatamento e áreas de agricultura registrados na Microrregião de Paragominas, Pará.

Tabela 1. Crescimento dos focos de calor, desmatamento e áreas de agricultura registrados na Microrregião de Paragominas, Pará.

\begin{tabular}{|c|c|c|c|c|c|c|c|}
\hline \multirow[b]{2}{*}{ Ano } & \multicolumn{3}{|c|}{ Incidência } & \multirow[b]{2}{*}{ Período } & \multicolumn{3}{|c|}{ Crescimento (\%) } \\
\hline & $\begin{array}{l}\text { Focos de } \\
\text { calor }\left(n^{\circ}\right)\end{array}$ & $\begin{array}{c}\text { Desmatamento } \\
\text { (ha) }\end{array}$ & $\begin{array}{c}\text { Agricultura } \\
\text { (ha) }\end{array}$ & & $\begin{array}{c}\text { Focos de } \\
\text { calor }\end{array}$ & Desmatamento & Agricultura \\
\hline 2002 & 5012 & 141471,96 & 30,33 & 2002-2006 & 128,75 & $-75,71$ & 52082,66 \\
\hline 2006 & 11465 & 34366,31 & 15826,19 & 2006-2010 & $-22,79$ & $-31,36$ & 150,21 \\
\hline 2010 & 8852 & 23589,02 & 39597,91 & 2010-2014 & 36,35 & $-65,92$ & 218,93 \\
\hline 2014 & 12070 & 8040,29 & 126290,82 & 2014-2018 & $-91,41$ & 12,67 & 66,59 \\
\hline 2018 & 1037 & 9058,84 & 210390,54 & $2002-2018$ & $-79,31$ & $-93,60$ & 693607,07 \\
\hline
\end{tabular}

No ano de 2002 verificou-se que os focos de calor estavam concentrados próximos às áreas desmatadas, rodovias e sedes municipais, havendo distribuição destes por toda a microrregião. Além disso, nota-se concentração dos focos de calor em alguns assentamentos, porém, não há registros nas terras indígenas (Figura 3a). 


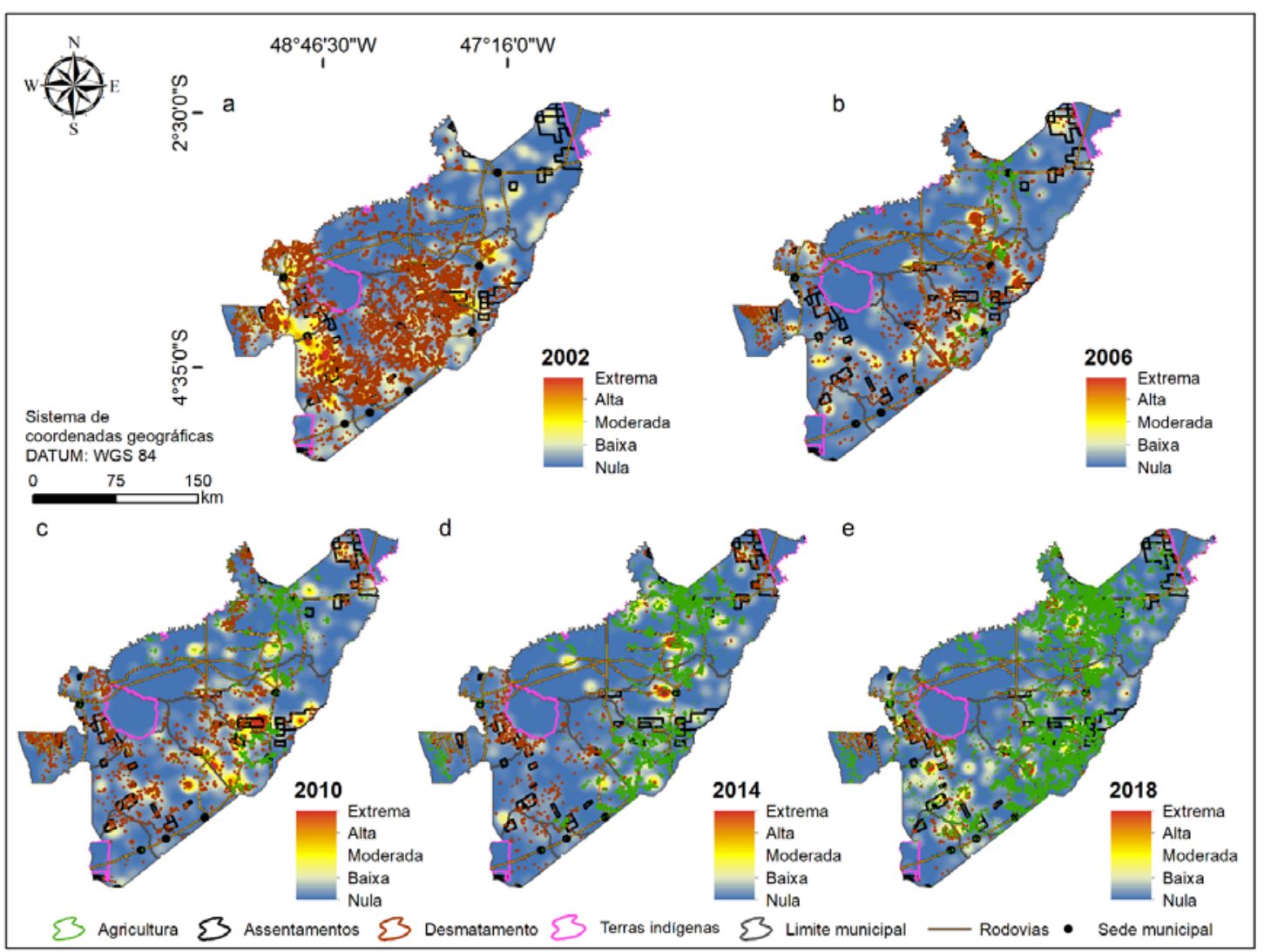

Figura 3. Mapa de densidade de kernel dos focos de calor, bem como áreas desmatadas e agrícolas registrados na microrregião de Paragominas, Pará.

Em 2006 há maior concentração dos focos de calor nos municípios de Paragominas e Ulianópolis, sendo estes em áreas de desmatamento. Nos demais municípios há concentração moderada. Nota-se que a fronteira agrícola se expandiu principalmente às margens das rodovias, além disso, há concentração moderada de focos de incêndio nas suas proximidades (Figura 3b).

0 ano de 2010 evidenciou maior densidade de focos nos Municípios de Dom Eliseu, Rondon do Pará e Ulianópolis, estando essa densidade relacionada a áreas agrícolas e desmatamento, além destes, em Ulianópolis também houve assentamentos com alta incidência dos focos de calor (Figura 3d).

No ano de 2014 áreas densas foram constatadas em Paragominas e Ulianópolis. Em Paragominas há uma grande evolução da fronteira agrícola, sendo a maior parte dos focos relacionados a essa atividade, bem como à proximidade com as rodovias. No Município de Ulianópolis a alta concentração está ligada às rodovias, bem como a sede do município. Áreas com densidade moderada foram identificadas em toda microrregião, sendo estas associadas as rodovias e áreas de agricultura (Figura 3e).

Em 2018, as áreas de agricultura se expandem por todos os municípios da microrregião, com maior destaque para Dom Eliseu, Paragominas e Ulianópolis. Regiões mais adensadas de focos de calor foram observadas em Dom Eliseu, Paragominas e Rondon do Pará, sendo estes próximos a regiões agrícolas. Além disso, em Goianésia do Pará há focos relacionados ao desmatamento, sendo o município que mais desflorestou neste ano (Figura 3f). 


\section{Discussão}

A exploração madeireira era a principal fonte de renda dos municípios da microrregião entre os anos 2000 e 2008, de tal maneira que isto permitiu que Paragominas, Ulianópolis, Dom Eliseu e Rondon do Pará entrassem para a lista dos maiores desflorestadores da Amazônia (MMA, 2008), o que explica as altas taxas de desmatamento em 2002 (Tabela 1) e os focos de incêndio relacionados a estes (Figura 3a).

Em 2006, a grande expansão da fronteira agrícola, principalmente do cultivo da soja, elevou a microrregião a segunda posição do valor bruto da produção agropecuária da região norte (IBGE, 2020). Vale ressaltar que, geralmente, as agriculturas são implantadas próximo as rodovias, com vistas em facilitar o transporte de insumos e escoamento da produção (Santos et al., 2017), o que acarreta a incidência dos focos de calor, devido ao tráfego de veículos. Além disso, por se tratar de uma agricultura anual, é comum que as áreas de soja permaneçam com o solo exposto durante o período de entressafra, aumentando a absorção da luz solar e consequentemente a temperatura (Gutiérrez-Velez et al., 2014), ocasionando a detecção de focos de calor por satélites.

No ano de 2008 foi efetuada as operações Arco de fogo, Arco verde e Programa municípios verde, as quais visavam reduzir o desmatamento da região Amazônica, bem como efetuar uma transição entre o modelo de produção predatória para sustentável (MMA, 2009). O sucesso dessas operações fez com que Paragominas fosse o primeiro município a sair da lista do desmatamento, reduzindo-o em mais de 90\% (Barreto e Araújo, 2012; Whately e Campanili, 2013). Posteriormente os demais municípios da microrregião conseguiram reduzir suas taxas de desmatamento, o que contribuiu para a redução dos focos de calor no ano de 2010.

Em 2013 e 2014 os municípios da microrregião de Paragominas foram os líderes da produção agrícola do estado, com ênfase para Dom Eliseu, Paragominas, Rondon do Pará e Ulianópolis (FAPESPA, 2017), trazendo consigo os impactos da agricultura na incidência dos focos de calor e corroborando com os resultados encontrados neste trabalho. No ano de 2018 este cenário se repetiu, sendo 48\% da área de agricultura do Pará implantada na microrregião de Paragominas, na qual os municípios Dom Eliseu, Paragominas, Rondon do Pará e Ulianópolis estavam entre os cinco maiores produtores do estado (Mapbiomas development team, 2019).

Estudos similares comprovaram que a expansão da fronteira agrícola aumenta a suscetibilidade aos focos de incêndio, sendo a proximidade com estradas e o tamanho das áreas os fatores que mais influenciam nos focos de calor (Figura 4) (Koutsias et al., 2013; Castañeda Rojas et al., 2015; Ibarra-Montoya e Huerta-Martínez, 2016; Marín et al., 2018).

As políticas de combate ao desmatamento foram essenciais para conter o seu avanço, além de que, aliadas a Moratória da soja foram impulsionadoras do crescimento das áreas agrícolas no período de estudo (Jusys, 2018). A moratória da soja foi um acordo voluntário, no qual os comerciantes concordaram em não comprar soja cultivadas em áreas desmatadas da Amazônia após julho de 2006 (Gibbs et al., 2015). Estes eventos explicam o porquê do crescimento da agricultura na microrregião de Paragominas, bem como a redução do desmatamento (Figura 4). 


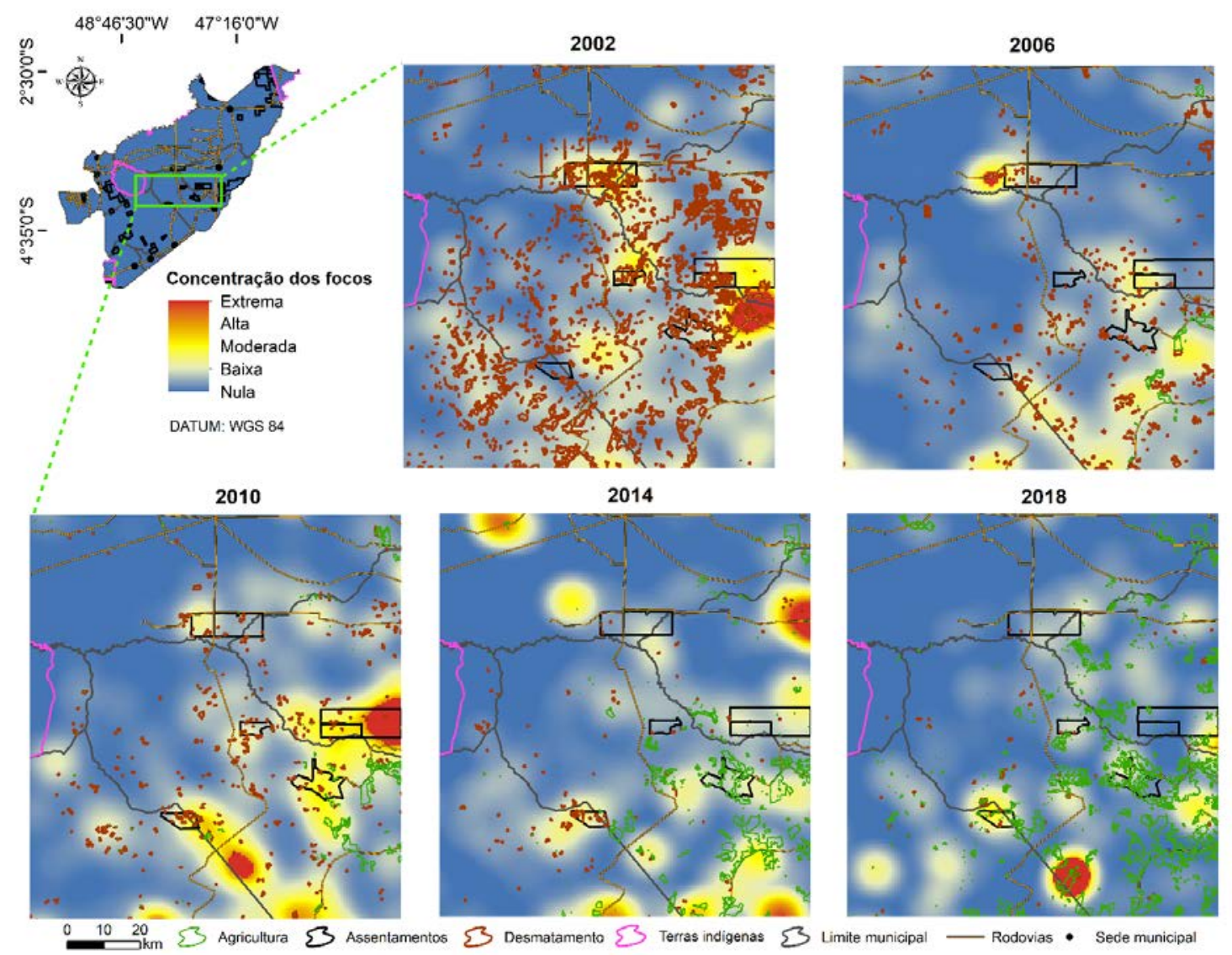

Figura 4. Focos de calor nos entornos das rodovias, áreas agrícolas, desmatamento e assentamentos na microrregião de Paragominas, Pará.

De maneira geral os focos de calor estavam localizados em assentamentos, sendo o Luís Inácio, localizado em Paragominas, frequente em todos os anos de análise. Vale salientar que a microrregião possui 41 assentamentos cadastrados, de tal maneira que nessas áreas predomina a agricultura familiar, a qual utiliza o sistema de corte e queima da vegetação, devido ser uma prática cultural, bem como a ausência de maquinário, insumos e assistência técnica (Ávila e Wadt, 2015; INCRA, 2017; Martínez-Fernández et al., 2013). Contraponto, a baixa incidência de focos de calor e desmatamento nas terras indígenas (Figura 4), deve-se principalmente a eficiência das políticas públicas de preservação, possibilitando a manutenção da biodiversidade, sem que haja alterações na paisagem (Brito e Barbosa, 2015).

Existem técnicas alternativas eficazes ao sistema de corte e queima (e. g. Alley, Tritucap), contudo a falta de acesso a insumos, crédito assistência técnica e tecnologia impossibilitam a substituição dessa técnica (Hands et al., 1995; Sampaio et al., 2008; Carmenta et al., 2016; Devisscher et al., 2016b). Vale ressaltar que os assentamentos, geralmente, localizam-se em áreas de difícil acesso, com estradas de terra em situações precárias, o que dificulta o acesso de insumos e escoamento da produção, assim, melhorar o acesso a estes locais deve ser incluído como política pública para mitigar o uso do fogo como ferramenta agrícola (Carmenta et al., 2016). 


\section{Considerações finais}

Os fatores antrópicos influenciam na dinâmica espaço-temporal dos focos de calor, uma vez que convertem a floresta densa em áreas de vegetação pouco densa, aumentando a absorção de calor pelo solo. Até o ano de 2010, o desmatamento e a exploração madeireira foram os grandes responsáveis pela dinâmica dos focos de calor na microrregião. Deste ano até 2018, a agricultura ocasionou a incidência dos focos de calor, uma vez que aumenta a absorção de luz no solo, bem como o tráfego de veículos nas rodovias. Tais fatores aliados ao sistema de corte e queima praticado nos assentamentos são os principais causadores dos focos de calor na Microrregião de Paragominas, Pará.

Desta forma, é imprescindível a intensificação de políticas públicas que visem a conscientização dos agricultores familiares, frente às injurias ocasionadas por esse sistema, bem como o fomento de técnicas alternativas e garantia de assistência técnica. Enquanto nas grandes áreas de agricultura, o cultivo na entressafra evitaria que o solo ficasse exposto, o que poderia reduzir a absorção de luz solar. Somente assim a influência dos fatores antrópicos sobre a incidência dos focos de calor seria mitigada, reduzindo os riscos de queimadas.

\section{Conflito de interesses}

Os autores declaram não haver conflito de interesses.

\section{Referências}

Albuquerque, M. F.; Souza, E. B.; Oliveira, M. C. F.; Souza Júnior, J. A. Precipitação nas mesorregiões do Estado do Pará: climatologia, variabilidade e tendências nas últimas décadas (1978-2008). Revista Brasileira de Climatologia, v. 6, n. 6, p. 151-168, 2010. https://doi.org/10.5380/abclima.v6i0.25606

Alvares, C. A.; Stape, J. L.; Sentelhas, P. C.; Gonçalves, J. L. M; Sparovek, G. Köppen's climate classification map for Brazil. Meteorologische Zeitschrift, v. 22, n. 6, p. 711-728, 2013. https://doi.org/10.1127/0941-2948/2013/0507

Aragão, L. E. O. C. Environmental science: The rainforest's water pump. Nature, v. 489, n. 7415, p. 217-218, 2012. https://doi.org/10.1038/nature11485

Aragão, L. E. O. C.; Shimabukuro, Y. E. The incidence of fire in Amazonian forests with implications for REDD. Science, v. 328, n. 5983, p.1275-1278, 2010. https://doi.org/10.1126/science.1186925

Armenteras, D.; Retana, J. Dynamics, patterns and causes of fires in Northwestern Amazonia. PLoS ONE, v. 7, n. 4, 2012. https://doi.org/10.1371/journal.pone.0035288

Ávila, M. M.; Wadt, P. G. S. Avaliação do impacto ambiental em assentamentos rurais do Estado do Acre, na Amazônia Brasileira. Revista Eletrônica de Biologia, v. 8, n. 1, p. 54-77, 2015.

Barreto, P.; Araújo, E. O Brasil atingirá sua meta de redução do desmatamento? Belém: Imazon, 2012. v. 1.

Bittencourt, D. Z.; Bazzan, T.; Lahm, R. A. Análise temporal e espacial dos focos de calor no Município de São Francisco de Paula, RS, no período entre 2003 e 2012. Caderno de Estudos Geoambientais, v. 4, n. 1, p. 37-55, 2013. 
Brito, A. L. C.; Barbosa, E. M. A. Gestão ambiental das terras indígenas e de seus recursos naturais: fundamentos jurídicos, limites e desafios. Veredas do Direito, v. 12, n. 24, p. 97-123, 2015. https://doi.org/10.18623/rvd.v12i24.544

Carmenta, R.; Blackburn, G. A.; Davies, G.; Sassi, C.; Lima, A.; Parry, L.; Tych, W.; Barlow, J. Does the establishment of sustainable use reserves affect fire management in the humid tropics? PloS ONE, v. 11, n. 2, p. 1-19, 2016. https://doi.org/10.1371/journal.pone. 0149292

Castañeda Rojas, M. F.; Agramont, A. R. E.; Ruiz, M. L. V.; Bernal, E. G. N. Evaluación forestal y de combustibles en bosques de pinus Hartwegii en el Estado de México según densidades de cobertura y vulnerabilidad a incendios. Madera y Bosques, v. 21, n. 2, p. 45-58, 2015.

Devisscher, T.; Anderson, L. O.; Aragão, L. E. O. C.; Galván, L.; Malhi, Y. Increased wildfire risk driven by climate and development interactions in the Bolivian Chiquitania, Southern Amazonia. PloS ONE, v. 11, n. 9, p. 1-29, 2016a. https://doi.org/10.1371/journal.pone. 0161323

Devisscher, T.; Boyd, E.; Malhi, Y. Anticipating future risk in social-ecological systems using fuzzy cognitive mapping: The case of wildfire in the Chiquitania, Bolivia. Ecology and Society, v. 21, n. 4, 2016b. https://doi.org/10.5751/ES-08599-210418

FAPESPA - Fundação Amazônia de Amparo a Estudos e Pesquisas. Boletim agropecuário do Estado do Pará 2015. Belém: FAPESPA, 2017.

Gibbs, H. K.; Rausch, L.; Munger, J.; Schelly, I.; Morton, D. C.; Noojipady, P.; Soares-Filho, B.; Barreto, P.; Micol, L.; Walker, N. F. Brazil's soy moratorium. Science, v. 347, n. 6220, p. 377-378, 2015. https://doi.org/10.1126/science.aaa0181

Gutiérrez-Velez, V. H.; Uriarte, M.; Defries, R.; Pinedo-Vasquez, M.; Fernandes, K.; Ceccato, P.; Baethgen, W.; Padoch, C. Land cover change interacts with drought severity to change fire regimes in Western Amazonia. Ecological Applications, v. 24, n. 6, p. 1323-1340, 2014. https://doi.org/10.1890/13-2101.1

Hands, M.; Harrison, A. F.; Bayliss-Smith, T. Phosphorus dynamics in slash-and-burn and alley cropping systems of the humid tropics. In: Tiessen, H. (Ed.). Phosphorus in the global environment. Chichester: Scope/Unep, 1995. p. 155-170.

Ibarra-Montoya, J. L.; Huerta-Martínez, F. M. Modelado espacial de incendios: una herramienta predictiva para el Bosque La Primavera, Jalisco México. Revista Ambiente e Água, v. 11, n. 1, p. 35-49, 2016. https://doi.org/10.4136/ambi-agua.1536

IBGE - Instituto Brasileiro de Geografia e Estatística. Geociências. 2019. Disponível em: <https://www.ibge.gov.br/geociencias/downloads-geociencias.html>. Acesso em: 22 mar. 2019.

IBGE - Instituto Brasileiro de Geografia e Estatística. Censo Agropecuário. 2020. Disponível em: <https://www.ibge.gov.br/estatisticas/economicas/agricultura-epecuaria/21814-2017-censo-agropecuario.html?=\&t=o-que-e>. Acesso em: 17 mar. 2020.

INCRA - Instituto Nacional de Colonização e Reforma Agrária. Incra nos estados Informações gerais sobre os assentamentos da reforma agrária. 2019. Disponível em: <http://painel.incra.gov.br/sistemas/index.php>. Acesso em: 5 jan. 2019.

INPE - Instituto Nacional de Pesquisas Espaciais. PRODES - Monitoramento de Floresta Amazônica por Satélite. 2019. Disponível em: <http://www.obt.inpe.br/obt/assuntos/programas/amazonia/prodes>. Acesso em: 14 abr. 2019. 
INPE - Instituto Nacional de Pesquisas Espaciais. Portal do Monitoramento de Queimadas e Incêndios. 2020a. Disponível em: <http://www.inpe.br/queimadas>. Acesso em: 20 mar. 2020.

INPE - Instituto Nacional de Pesquisas Espaciais. Programa Queimadas. 2020b. Disponível em: <http://queimadas.dgi.inpe.br//queimadas/portal>. Acesso em: 16 fev. 2020b.

Jusys, T. Changing patterns in deforestation avoidance by different protection types in the Brazilian Amazon. PloS ONE, v. 13, n. 4, p. 1-16, 2018. https://doi.org/10.1371/journal. pone.0195900

Koutsias, N.; Xanthopoulos, G.; Founda, D.; Xystrakis, F.; Nioti, F.; Pleniou, M.; Mallinis, G.; Arianoutsou, M. On the relationships between forest fires and weather conditions in Greece from long-term national observations (1894-2010). International Journal of Wildland Fire, v. 22, p. 493-507, 2013. https://doi.org/10.1071/WF12003

Koutsias, N.; Kalabokidis, K. D.; Allgöwer, B. Fire occurrence patterns at landscape level: Beyond positional accuracy of ignition points with kernel density estimation methods. Natural Resource Modeling, v. 17, n. 4, p. 359-375, 2004. https://doi.org/10.1111/ j.1939-7445.2004.tb00141.x

Lima, A.; Silva, T. S. F.; Aragão, L. E. O. C.; Feitas, R. M.; Adami, M.; Formaggio, A. R.; Shimabukuro, Y. E. Land use and land cover changes determine the spatial relationship between fire and deforestation in the Brazilian Amazon. Applied Geography, v. 34, p. 239-246, 2012. https://doi.org/10.1016/j.apgeog.2011.10.013

Mapbiomas Development Team. Coleções Mapbiomas. 2019. Disponível em: <https://mapbiomas.org/colecoes-mapbiomas-1>. Acesso em: 16 fev. 2019.

Marín, P.; Julio, C. J.; Arturo, R. D.; Jose, V. D. Drought and spatiotemporal variability of forest fires across Mexico. Chinese Geographical Science, v. 27, n. 6, p. 1-13, 2018. https://doi.org/10.1007/s11769-017-0928-0

Martínez-Fernández, J.; Chuvieco, E.; Koutsias, N. Modelling long-term fire occurrence factors in Spain by accounting atmospheric for local variations with geographically weighted regression. Natural Hazards and Earth System Sciences, v. 13, p. 311-327, 2013. https://doi.org/10.5194/nhess-13-311-2013

Middendorp, R. S.; Vlam, M.; Rebel, K. T.; Baker, P. J.; Bunyavejchewin, S.; Zuidema, P. A. Disturbance history of a seasonal tropical forest in Western Thailand: A spatial dendroecological analysis. Biotropica, v. 45, n. 5, p. 578-586, 2013. https://doi.org/ 10.1111/btp.12051

MMA - Ministério do Meio ambiente. MMA divulga lista dos municípios que mais desmataram em 2007. Disponível em: <http://www.mma.gov.br/informma/item/4590mmadivulga-lista-dos-municipios-que-mais-desmataram-em-2007>. Acesso em: 18 mar. 2020.

MMA - Ministério do Meio ambiente. Plano de ação para prevenção e controle do desmatamento da Amazônia Legal. Brasília: MMA, 2009.

QGIS Development Team. QGIS Versão 2.18. Las Palmas: QGIS Development Team, 2016.

Sampaio, C. A.; Kato, O. R.; Nascimento-e-Silva, D. Sistema de corte e trituração da capoeira sem queima como alternativa de uso da terra, rumo à sustentabilidade florestal no nordeste paraense. Revista de Gestão Social e Ambiental, v. 2, n. 1, p. 41-53, 2008. https://doi.org/10.5773/rgsa.v2i1.60 
Santos, H. G.; Jacomine, P. K. T.; Anjos, L. H. C.; Oliveira, V. A.; Lumbreras, J. F.; Coelho, M. R.; Almeida, J. A.; Araújo Filho, J. C.; Oliveira, J. B.; Cunha, T. J. F. Sistema brasileiro de classificação de solos. 5. ed. Brasília: EMBRAPA, 2018.

Santos, T. N. O.; Souza, E. L.; Araújo, M. F. A Reinvenção do agronegócio no sudeste paraense: uma análise do avanço da soja e sua relação com a sustentabilidade. Revista de Gestão do Agronegócio da UNIPAMPA, v. 2, n. 2, p. 177-190, 2017.

Whately, M.; Campanili, M. Programa Municípios Verdes: lições aprendidas e desafios para 2013/2014. 1. ed. Belém: Governo do Pará, 2013. 